\title{
Основные генетические и биологические
} маркеры псориаза

\author{
О.О. Мельниченко ${ }^{\bowtie 1}$, Е.В. Денисова ${ }^{1,2}$, О.В. Жукова ${ }^{1,3}$, Н.Н. Потекаев ${ }^{1,4}$ \\ 'ГБУз «Московский научно-практический центр дерматовенерологии и косметологии» Департамента здравоохранения \\ г. Москвы, Москва, Россия; \\ ФГБУН «Центр теоретических проблем физико-химической фармакологии» РАН, Москва, Россия; \\ ${ }^{3}$ ФГАОУ ВО «Российский университет дружбы народов», Москва, Россия; \\ ${ }^{4}$ ФГАОУ ВО «Российский национальный исследовательский медицинский университет им. Н.И. Пирогова» Минздрава России, \\ Москва, Россия
}

\section{Аннотация}

Обоснование. Псориаз - это хроническое воспалительное аутоиммунное заболевание, характеризующееся чрезмерно аберрантной гиперпролиферацией кератиноцитов. Патогенез псориаза сложен, и точный механизм, несмотря на многочисленные исследования, до сих пор остается неясным. Сложные генетические связи играют важную роль в патогенезе этого дерматологического заболевания. В развитии псориаза задействовано большое количество генов, также ассоциированных с другими заболеваниями. Широкий спектр наблюдаемых у пациентов с псориазом коморбидных состояний зачастую весьма затрудняет терапию дерматоза. Понимание роли некоторых генов в патогенезе псориатического процесса позволит разработать более эффективное целевое лечение, направленное на блокирование соответствующих воспалительных сигнальных путей и молекул.

Цель. Проанализировать и систематизировать основные генетические и биологические маркеры псориаза.

Материалы и методы. В исследование включены исследовательские статьи, посвященные генетическому анализу псориаза. Использовались реферативные базы ResNet, PubMed и eLibrary.

Результаты и обсуждение. В результате проведенного детального анализа литературных источников, посвященных псориатической болезни, определен круг основных генетических и биологических маркеров. Уделено внимание роли и влиянию однонуклеотидных полиморфизмов, которые позволяют установить четкую ассоциацию ряда генов, задействованных в развитии псориаза. Отдельно рассматривались гены с измененной экспрессией при псориатическом процессе.

Заключение. Выявленные биомаркеры могут применяться в направленной биологической терапии псориаза с использованием биологических модуляторов, которые блокируют передачу сигналов.

Ключевые слова: псориаз, генетические маркеры, биомаркеры

Для цитирования: Мельниченко О.О., Денисова Е.В., Жукова О.В., Потекаев Н.Н. Основные генетические и биологические маркеры псориаза. Consilium Medicum. 2021; 23 (8): 672-675. DOI: 10.26442/20751753.2021.8.201188

ORIGINAL ARTICLE

\section{Basic genetic and biological markers of psoriasis}

\author{
Olga O. Melnichenko ${ }^{\bowtie 1}$, Elena V. Denisova ${ }^{1,2}$, Olga V. Zhukova ${ }^{1,3}$, Nikolay N. Potekaev ${ }^{1,4}$ \\ 'Moscow Scientific and Practical Center of Dermatology, Venereology and Cosmetology, Moscow, Russia; \\ ${ }^{2}$ Center for Theoretical Problems of Physicochemical Pharmacology, Moscow, Russia; \\ ${ }^{3}$ Peoples' Friendship University of Russia (RUDN University), Moscow, Russia; \\ ${ }^{4}$ Pirogov Russian National Research Medical University, Moscow, Russia
}

\section{Abstract}

Background. Psoriasis is a chronic inflammatory autoimmune disease characterized by an excessively aberrant hyperproliferation of keratinocytes. The pathogenesis of psoriasis is complex, and the exact mechanism, despite numerous studies, is still unclear. Complex genetic relationships play an important role in the pathogenesis of this skin disease. A large number of genes that are also associated with other diseases are involved in the development of psoriasis. The variety of comorbidities in patients with psoriasis often present challenges to the treatment for dermatosis. Understanding the role of certain genes in the pathogenesis of psoriasis will contribute the development of more effective targeted therapy aimed at blocking the corresponding inflammatory signaling pathways and molecules.

Aim. To analyze and systematize the basic genetic and biological markers of psoriasis.

\section{Информация об авторах / Information about the authors}

Мельниченко Ольга Олеговна - канд. мед. наук, врачдерматовенеролог ГБУЗ МНПЦДК. E-mail: dr.melnichenko@gmail.com; ORCID: 0000-0002-0522-3225

Денисова Елена Валерьевна - канд. мед. наук, зам. зав. филиала по медицинской части ГБУЗ МНПЦДК, ст. науч. сотр. ФГБУН ЦТП ФХФ. ORCID: 0000-0002-4887-284X

Жукова Ольга Валентиновна - д-р мед. наук, проф., глав. врач ГБУЗ МНПЦДК, зав. каф. кожных и венерических болезней Медицинского института ФГАОУ ВО РУДН. E-mail: klinderma@inbox.ru; ORCID: 0000-0001-5723-6573

Потекаев Николай Николаевич - д-р мед. наук, проф., дир. ГБУз МНПЦДК, зав. каф. кожных болезней и косметологии ФГАОУ ВО «РНИМУ им. Н.И. Пирогова», президент Национального альянса дерматологов и косметологов. E-mail: klinderma@mail.ru; ORCID: 0000-0002-9578-5490
Olga O. Melnichenko - Cand. Sci. (Med.), Moscow Scientific and Practical Center of Dermatology, Venereology and Cosmetology. E-mail: dr.melnichenko@gmail.com; ORCID: 0000-0002-0522-3225

Elena V. Denisova - Cand. Sci. (Med.), Moscow Scientific and Practical Center of Dermatology, Venereology and Cosmetology, Center for Theoretical Problems of Physicochemical Pharmacology. ORCID: 0000-0002-4887-284X

Olga V. Zhukova - D. Sci. (Med.), Prof., Moscow Scientific and Practical Center of Dermatology, Venereology and Cosmetology, Peoples' Friendship University of Russia (RUDN University).

E-mail: klinderma@inbox.ru; ORCID: 0000-0001-5723-6573

Nikolay N. Potekaev - D. Sci. (Med.), Prof., Moscow Scientific and Practical Center of Dermatology, Venereology and Cosmetology, Pirogov Russian National Research Medical University.

E-mail: klinderma@mail.ru; ORCID: 0000-0002-9578-5490 
Materials and methods. The study included research articles on the genetic analysis of psoriasis. The ResNet, PubMed and eLibrary databases were used.

Results and discussion. Basic genetic and biological markers were identified by analysis of literature sources devoted to psoriasis. Attention is paid to the role and effects of single nucleotide polymorphisms, which make it possible to establish a clear association of a number of genes involved in the development of psoriasis. Genes with altered expression in the psoriatic process were considered separately.

Conclusion. The identified biomarkers can be used in targeted biological therapy of psoriasis using biological modulators that block signaling.

Keywords: psoriasis, genetic markers, biomarkers

For citation: Melnichenko OO, Denisova EV, Zhukova OV, Potekaev NN. Basic genetic and biological markers of psoriasis. Consilium Medicum. 2021; 23 (8): 672-675. DOI: 10.26442/20751753.2021.8.201188

\section{Введение}

Псориаз, как и большинство аутоиммунных заболеваний, представляет собой иммуноопосредованный дерматоз, находящийся под влиянием генетических и эпигенетических модификаций, которые могут быть вызваны факторами окружающей среды [1]. Псориаз - очень распространенное заболевание, которым страдает около $3 \%$ населения мира [2]. Псориаз может иметь различные клинические проявления и не имеет определенного генетического маркера заболевания, из-за чего бывают сложности в диагностике. В результате псориаз по-прежнему остается клиническим диагнозом, который определяется морфологическими данными и внешними проявлениями.

Для псориаза характерны нарушения дифференцировки и пролиферации кератиноцитов, обусловленные аутоиммунной реакцией Т-лимфоцитов и макрофагов против клеток кожи. ДНК распадающихся кератиноцитов является антигеном, который вызывает воспаление, ангиогенез и пролиферацию иммунокомпетентных клеток. Дермальные дендритные клетки презентируют антиген Т-хелперам (Th0)-лимфоцитам и стимулируют пролиферацию Т-киллеров и Т-хелперов 1-го типа, секретирующих разные химические сигналы-цитокины: фактор некроза опухоли (ФНО)- $\alpha$, интерлейкины (ИЛ)- $1 \beta, 6$, интерферон (ИФН)- $\gamma$ и ИЛ-17, которые вызывают воспаление, ИЛ-22, вызывающий усиленную пролиферацию кератиноцитов и нарушение их нормального созревания и дифференцировки. Реагируя на эти цитокины, кератиноциты продуцируют ИЛ-1, 6 и ФНО-а, которые вызывают хемотаксис новых иммунных клеток в месте воспаления, их повышенную пролиферацию, дальнейшее развитие и усиление воспалительной реакции [3-5].

Исследования, проведенные за последнее десятилетие, позволили выявить множество генетических маркеров развития псориаза. В статье будут рассмотрены наиболее важные маркеры, которые широко используются в направленной биологической терапии псориаза.

\section{Генетические маркеры}

Роль генетики является важнейшим фактором риска развития псориаза. Популяционные исследования показали, что заболеваемость псориазом выше среди родственников пациентов 1 и 2-й степени родства, чем у остального населения. Исследования конкордантности заболеваний среди близнецов показали, что риск псориаза среди монозиготных близнецов в 2-3 раза выше, чем среди дизиготных [6]. Все эти факты указывают на генетический компонент в патогенезе псориаза.

Роль генетики изучалась с помощью семейных и близнецовых исследований и полногеномных ассоциаций (genome-wide association studies - GWAS). Псориаз не передается по менделевской модели, однако наблюдается семейная предрасположенность [7]. Положительный семейный анамнез значительно увеличивает риск заболеваемости среди родственников пациентов 1 и 2-й степени родства по сравнению с населением в целом [6]. Генетические исследования показали, что аллель $H L A-C w 6$ гена HLA-C (Human Leukocyte Antigen C) объясняет большую часть известной наследственности псориаза $[8,9]$. GWAS успешно применены для исследования генетической архитектуры псориаза, идентифицировано более 15 раз- личных локусов восприимчивости к псориазу (PSORS) в результате генетического анализа семей, пораженных псориазом [10].

Широкое изучение роли однонуклеотидных полиморфизмов (SNP) позволило установить четкую ассоциацию ряда генов с развитием псориаза. Выявлены значимая ассоциация с риском развития псориаза генов семейства поздних ороговевших конвертов LCE3B/3C [11], которые участвуют в формировании эпидермальных клеток и кожного барьера и высоко представлены в псориатических поражениях, и гены NO-синтаз NOS1, NOS2 и NOS3 [12-15], которые влияют на поддержание воспалительного процесса в пораженной коже и являются регулятором роста и дифференцировки кератиноцитов. Совсем недавно обнаружена ассоциация генов [COMT (rs4680), DBH (rs141116007), CCKAR (rs1800857) и CCKBR (rs1805002)], отвечающих за психоэмоциональные расстройства, с псориазом [16-20]. Эти результаты впервые на генетическом уровне подтвердили, что в развитии заболевания в качестве факторов предрасположенности участвуют психические расстройства, а также подтверждены данные по корреляции дерматологических заболеваний с патологической тревожностью и стрессом [21]. Накопилось множество данных о важной роли генетических вариантов ИЛ-23R и 23А в патогенезе псориаза. Помимо ингибирующих вариантов обнаружен вариант гена IL23R R381Q, который не ингибирует напрямую активность клеток Th17, но оказывает защитный эффект за счет избирательного ослабления индуцированных ИЛ-23 клеток Th17, что существенно отличается от предыдущих мутаций ИЛ-23R $[22,23]$. Все чаще обнаруживается, что однонуклеотидные замены в микроРНК, например MIR22, также вносят вклад в патогенез псориаза [24].

\section{Биомаркеры псориаза}

Значительный вклад в понимание патогенеза внесли работы по изучению транскрипционной активности генов. Продемонстрировано, что уровни матричной РНК и белка ИЛ-17 повышаются в крови или биоптатах пораженной псориазом кожи человека $[25,26]$. ИЛ-17 в основном продуцируется клетками Th17, но недавно обнаружено, что клетки врожденного иммунитета, включая $\gamma \delta$ Т-клетки, нейтрофилы и тучные клетки, участвуют в секреции ИЛ-17 при псориазе [27]. ИЛ-17 напрямую участвует в усилении пролиферации кератиноцитов и ингибировании дифференцировки кератиноцитов через медиатор REG3A, белок с антимикробными функциями, участвующий в заживлении ран [28]. ИЛ-17А стимулирует выработку кератиноцитами хемокинов и антимикробных пептидов, таких как S100-белки. Существенное повышение экспрессии S100A7, S100A8 и S100A9 в пораженной псориазом коже связано с высокими уровнями ИЛ-17 [29-31], что в свою очередь способствует привлечению клеток Th17 и продуцированию еще больше ИЛ-17, а это приводит к возникновению петли положительной обратной связи, которая поддерживает воспалительную реакцию псориаза [32]. Фактически ИЛ-17 участвует как в развитии многих аутоиммунных заболеваний, включая псориаз, так и в иммунной защите. Так, ИЛ-17 оказывает защитное влияние на развитие заболевания, подавляя ФНО- $\alpha$-индуцированную продукцию CCL27 за счет индукции COX-2 в кератиноцитах человека, 
что в конечном итоге снижает дисфункцию кератиноцитов при псориазе [33].

ИЛ-23 способствует гиперпролиферации кератиноцитов и таким образом участвует в развитии псориаза. Дендритные клетки и макрофаги являются основными источниками ИЛ-23, уровни которого повышены при псориазе. Уровни матричной РНК и белка ИЛ-23 в псориатических поражениях кожи намного выше, чем в неповрежденной коже. Приведенные данные о высокой экспрессии гена и белка наряду с данными по полиморфизму одиночных нуклеотидов указывают на то, что ИЛ-23 является критическим цитокином в патогенезе заболевания [34].

Высокие уровни ИФН- $\gamma$ и ФНО-а действуют на кератиноциты и эндотелиальные клетки, приводя к активации, пролиферации и продукции антимикробных пептидов. Продемонстрировано, что ИФН- $\gamma$ более актуален на ранних стадиях заболевания, где он индуцирует перекрестное фосфорилирование киназ JАК2 и ЈАК3, что приводит к последующей активации STAT3. Последующая активация факторов STAT важна для роста клеток и способна регулировать многие гены, экспрессируемые в псориатических поражениях кожи [35]. Сверхэкспрессия гена STAT3 показана в пораженной псориазом коже, где она существенно снижалась после терапии [36].

ИФН- $\gamma$ способствует высвобождению цитокинов (ИЛ-23, ИЛ-1), хемокинов (CXCL10, CXCL11) и молекул адгезии из дендритных клеток. Исследования показывают, что ИФН- $\gamma$ может быть полезен в качестве биомаркера активности псориаза из-за его положительной корреляции с PASI $[37,38]$.

ФНО- $а$ регулирует антигенпрезентирующую способность дендритных клеток и помогает инфильтрации Т-клеток. Этот цитокин также обладает провоспалительными свойствами и при псориазе может способствовать выработке ИЛ-23 дендритными клетками [39].

Повышенный уровень ИЛ-22 при псориазе индуцирует опосредованную ИЛ-23 гиперпролиферацию кератиноцитов in vivo и in vitro посредством передачи сигналов STAT3 [40]. Комбинация ИЛ-22 и ИЛ-17 подавляет дифференцировку кератиноцитов и увеличивает их пролиферацию и подвижность, что приводит к задержке ядер в роговом слое, эпидермальной гиперплазии и удлинению эпидермальных сетчатых гребней, которые являются отличительным признаком кожных псориатических бляшек [41].

Рецепторы, активируемые пероксисомными пролифераторами (peroxisome proliferator-activated receptors - PPARs) представляют собой новую группу рецепторов, которые играют важную роль в физиологической системе млекопитающих и функционируют как транскрипционный фактор [42]. Известны три изоформы PPAR - PPAR $\alpha$, PAR $\beta / \delta$ и PPAR $\gamma$, которые обладают значительной гомологией последовательностей и структур, но демонстрируют разное тканевое распределение, селективность и чувствительность к лигандам, что приводит к регуляции разных наборов генов разными рецепторы $[43,44]$. PPAR $\gamma$ - наиболее исследуемый подтип PPAR, который экспрессируется преимущественно в жировой ткани, сердце, толстой кишке, почках, селезенке, кишечнике, скелетных мышцах, печени, макрофагах и коже. $\operatorname{PPAR} \gamma$ может действовать напрямую, отрицательно регулируя экспрессию провоспалительных генов лигандзависимым образом, противодействуя активности транскрипционных факторов. Продемонстрировано, что специфические лиганды PPAR $\gamma$ ингибируют продукцию многих медиаторов воспаления и цитокинов в различных типах клеток, включая моноциты, лимфоциты и эпителиальные клетки $[45,46]$. Зная, что псориаз представляет собой воспалительное заболевание кожи, характеризующееся гиперпролиферацией эпидермиса и аномальной дифференцировкой кератиноцитов, PPAR $\gamma$ может рассматриваться как новая потенциальная мишень для лечения [47].

\section{Заключение}

Все приведенные выше биомаркеры широко используется в направленной биологической терапии псориаза с применением биологических модуляторов, которые блокируют передачу сигналов. Как правило, эти новые методы лечения с использованием биологических модуляторов подразделяются на несколько широких групп: ингибиторы ФНО-а (этанерцепт, адалимумаб, инфликсимаб, голимумаб, цертолизумаб и онерцепт), ингибиторы ИЛ-17 (секукинумаб, нетакимаб), ингибиторы ИЛ-23 (устекинумаб), ингибиторы активации и передачи сигналов Т-клеток (алефацепт) и др. [48]. Однако генетика - это только часть патогенеза, и не стоит забывать про традиционные методы лечения псориаза, которые включают кортикостероиды, аналоги витамина $\mathrm{D}$, фототерапию и системные методы терапии $[49,50]$. Применение биомаркеров является новым шагом на пути к оптимизации лечения псориаза.

Конфликт интересов. Авторы заявляют об отсутствии конфликта интересов.

Conflict of interests. The authors declare no conflict of interest.

\section{Литература/References}

1. Seldin MF. The Genetics of Human Autoimmune Disease: A Perspective on Progress in the Field and Future Directions. J Autoimmun. 2015;64:1-12. DOl:10.1016/j.jaut.2015.08.015

2. Duffin $\mathrm{KC}$, Chandran V, Gladman DD, et al. Genetics of psoriasis and psoriatic arthritis: update and future direction. J Rheumatol. 2008;35:1449-53. PMID: 18609743

3. Nesterova AP, Klimov EA, Zharkova $M$, et al. Diseases of the skin and subcutaneous tissue. In Disease Pathways. Elsevier, 2020; p. 493-532. DOI:10.1016/B978-0-12-817086-1.00011-7

4. Nesterova AP, Yuryev A, Klimov EA, et al. Disease Pathways: An atlas of human disease signaling pathways. 1st ed. Elsevier: Waltham, 2019. DOI:10.1016/C2018-0-00586-1

5. Sobolev VV, Mezentsev AV, Ziganshin RH, et al. LC-MS/MS Analysis of Lesional and Normally Looking Psoriatic Skin Reveals Significant Changes in Protein Metabolism and RNA Processing. PLoS One. 2021;16:e0240956. DOI:10.1371/journal.pone.0240956

6. Farber EM, Nall L. The Natural History of Psoriasis in 5,600 Patients. Dermatology. 1974;148:1-18. DOl:10.1159/000251595

7. Allione A, Marcon F, Fiorito G, et al. Novel Epigenetic Changes Unveiled by Monozygotic Twin Discordant for Smoking Habits. PloS One. 2015;10:e0128265. DOl:10.1371/journal.pone.0128265

8. Park J-H, Wacholder S, Gail MH, et al. Estimation of Effect Size Distribution from GenomeWide Association Studies and Implications for Future Discoveries. Nat Genet. 2010;42:570-5. DOl:10.1038/ng.610

9. Nair RP, Stuart PE, Nistor I, et al. Sequence and Haplotype Analysis Supports HLA-C as the Psoriasis Susceptibility 1 Gene. Am J Hum Genet. 2006;78:827-51. DOl:10.1086/503821

10. Hiz MM, Kiliç S, Oymak S, et al. Psoriasis and Genetics. IntechOpen: Rijeka, 2017. DOl:10.5772/intechopen.68344

11. De Cid R, Riveira-Munoz E, Zeeuwen PLJM, et al. Deletion of the Late cornified envelope LCE3B and LCE3C genes as a susceptibility factor for psoriasis. Nat Genet. 2009;41:211-5. DOl:10.1038/ng.313

12. Coto-Segura P, Coto E, Mas-Vidal A, et al. Influence of Endothelial Nitric Oxide Synthase Polymorphisms in Psoriasis Risk. Arch Dermatol Res. 2011;303:445-9. DOI:10.1007/s00403-011-1129-9

13. Fu L, Zhao Y, Lu J, et al. Functional Single Nucleotide Polymorphism-1026C/A of Inducible Nitric Oxide Synthase Gene with Increased YY1-Binding Affinity Is Associated with Hypertension in a Chinese Han Population. J Hypertens. 2009;27:991-1000. DOl:10.1097/hjh.0b013e3283294bec

14. Klimov EA, Tretiakov AV, Gapanovich ES, et al. Evaluation of the role of polymorphic variants of no-synthases genes of in pathogenesis of psoriasis. Mol Meditsina Mol Med. 2018;16. DOl:10.29296/24999490-2018-04-11

15. Klimov E, Tretiakov A, Gapanovich E, et al. Assessment of the role of NO synthase genes polymorphisms in the pathogenesis of psoriasis. J Adv Med Med Res. 2018;26:1-6. DOl:10.9734/JAMMR/2018/41039

16. Sobolev V, Sakaniya L, Tretiakov A, et al. Association of GA Genotype of SNP Rs 4680 in COMT Gene with Psoriasis. Arch Dermatol Res. 2019;311:309-15. DOI:10.1007/s00403-019-01904-1

17. Sakaniya LR, Tretiakov AV, Shevtsova AA, et al. DBH gene polymorphism in psoriasis patients. Mol Meditsina Mol Med. 2019;17. DOl:10.29296/24999490-2019-04-09

18. Klimov E, Tretiakov A, Rudko 0 , et al. Psychodermatology: a molecular link between psoriasis and anxiety disorder. Acta Dermatovenerol Alp Pannonica Adriat. 2018;27. DOl:10.15570/actaapa.2018.38

19. Sobolev V, Klimov E, Tretiakov A, et al. 218 polymorphism of dopamine related genes in the light of psychodermatology: association with psoriasis. J Invest Dermatol. 2017;137:\$230. DOl:10.1016/j.jid.2017.07.215 
20. Соболев В.В., Третьяков А.В., Рудько О.И., и др. Психодерматология: молекулярная общность псориаза и тревожного расстройства. Эффективная фармакотерапия. 2017;15:10-5 [Sobolev VV, Tret'iakov AV, Rud'ko Ol, et al. Psikhodermatologiia: molekuliarnaia obshchnost' psoriaza i trevozhnogo rasstroistva. Effektivnaia farmakoterapiia. 2017;15:10-5 (in Russian)].

21. Данилин И.Е., Невозинска 3.А., Третьяков А.В., и др. Анализ взаимосвязи кожных и эмоциональных расстройств у больных псориазом. Вестник неврологии, психиатрии и нейрохирурzuu. 2020;11 [Danilin IE, Niewozinska ZA, Tretiakov AV, et al. Analysis of the relationship between skin and emotional disorders in patients with psoriasis. Bulletin of Neurology, Psychiatry and Neurosurgery. 2020;11 (in Russian)]. DOl: 10.33920/med-01-2011-02

22. Nair RP, Duffin KC, Helms C, et al. Genome-Wide Scan Reveals Association of Psoriasis with IL-23 and NF-KappaB Pathways. Nat Genet. 2009;41:199-204. DOl:10.1038/ng.311

23. Di Meglio P, Di Cesare A, Laggner U, et al. The IL23R R381Q Gene Variant Protects against ImmuneMediated Diseases by Impairing IL-23-Induced Th17 Effector Response in Humans. PLOS ONE. 2011;6:e17160. DOl: 10.1371/journal.pone.0017160

24. Соболев В.В., Третьяков А.В., Шевцова А.А., и др. Связь между однонуклеотидной заменой T>C в гене MIR22 и развитием псориаза. Эффективная фармакотерапия. 2018;34:18-20 [Sobolev VV, Tret'iakov AV, Shevtsova AA, et al, Sviaz' mezhdu odnonukleotidnoi zamenoi T>C V gene MIR22 i razvitiem psoriaza. Effektivnaia farmakoterapiia. 2018;34:18-20 (in Russian)].

25. Johansen $C$, Usher PA, Kjellerup RB, et al. Characterization of the Interleukin-17 Isoforms and receptors in lesional psoriatic skin. $\mathrm{Br} J$ Dermatol. 2009;160:319-24. DOl:10.1111/j.1365-2133.2008.08902.x

26. Sobolev WV, Sautin ME, Piruzian ES, et al. IL-17 gene expression levels in atherosclerosis and psoriasis. Prime. 2015;5:34-8. Available at: https://www.prime-journal.com/il-17-gene-expressionlevels-in-atherosclerosis-and-psoriasis/ Accessed: 13.08.2021.

27. Isailovic N, Daigo K, Mantovan A, Selmi C. Interleukin-17 and innate immunity in infections and chronic inflammation. J Autoimmun. 2015;60:1-11. DOI:10.1016/j.jaut.2015.04.006

28. Lai Y, Li D, Li C, et al. The Antimicrobial protein REG3A regulates keratinocyte proliferation and differentiation after skin injury. Immunity. 2012;37:74-84. DOI:10.1016/j.immuni.2012.04.010

29. Соболев В.В., Денисова Е.В., Корсунская И.М. Изменение экспрессии гена ऽ100A8 под воздействием лазерного излучения низкой интенсивности у больных псориазом. Эффрективная фармакотерапия. 2021;17:14-6 [Sobolev VV, Denisova EV, Korsunskaia IM. Izmenenie ekspressii gena S100A8 pod vozdeistviem lazernogo izlucheniia nizkoi intensivnosti u bol'nykh psoriazom. Effektivnaia farmakoterapiia. 2021;17:14-6 (in Russian)]. DOl:10.33978/2307-3586-2021-17-1-14-16

30. Ильина С.А., Золотаренко А.Д., Пирузян А.Л., и др. Экспрессия генов S100A8 и S100A9 в пораженной псориатическим процессом коже. Технологии живых систем. 2010;7:45-51 [ll'ina SA, Zolotarenko AD, Piruzian AL, et al. Ekspressiia genov S100A8 i S100A9 v porazhennoi psoriaticheskim protsessom kozhe. Tekhnologii zhivykh sistem. 2010;7:45-51 (in Russian)].

31. Ramirez-Carrozzi V, Sambandam A, Luis E, et al. IL-17C Regulates the innate immune function of epithelial cells in an autocrine manner. Nat Immunol. 2011;12:1159-66. DOI:10.1038/ni.2156

32. Kanda N, Koike S, Watanabe S. IL-17 Suppresses TNF-Alpha-Induced CCL27 Production through Induction of COX-2 in Human Keratinocytes. J Allergy Clin Immunol. 2005;116:1144-50. DOl:10.1016/j.jaci.2005.08.014

33. Cargill M, Schrodi SJ, Chang M, et al. A large-scale genetic association study confirms IL12B and leads to the identification of IL23R as psoriasis-risk genes. Am J Hum Genet. 2007;80:273-90. DOl:10.1086/511051

34. Johnson-Huang LM, Suárez-Fariñas M, Pierson $\mathrm{KC}$, et al. A single intradermal injection of IFN- $\gamma$ induces an inflammatory state in both non-lesional psoriatic and healthy skin. J Invest Dermatol. 2012:132:1177-87.DOl:10.1038/jid.2011.458
35. Соболев В.В., Денисова Е.В., Корсунская И.М. Изменение экспрессии гена STAT3 при лечении псориаза. Медицинский совет. 2020;12:71-4 [Sobolev VV, Denisova EV, Korsunskaya IM. Alteration of STAT3 gene expression in psoriasis treatment. Medical Council. 2020;12:71-4 (in Russian)]. DOI:10.21518/2079-701X-2020-12-71-74

36. Madonna S, Scarponi $C$, Sestito $R$, et al. The IFN-gamma-dependent suppressor of cytokine signaling 1 promoter activity is positively regulated by IFN regulatory factor-1 and Sp1 but repressed by growth factor independence-1 $\mathrm{b}$ and krüppel-like factor-4, and it is dysregulated in psoriatic keratinocytes. J/mmunol. 2010;185:2467-81. DOl:10.4049/jimmunol.1001426

37. Abdallah MA, Abdel-Hamid MF, Kotb AM, Mabrouk EA. Serum interferon-gamma is a psoriasis severity and prognostic marker. Cutis. 2009;84:163-8. PMID: 19842576

38. Zaba LC, Cardinale I, Gilleaudeau P, et al. Amelioration of epidermal hyperplasia by TNF inhibition is associated with reduced Th17 responses. J Exp Med. 2007;204:3183-94. D01:10.1084/jem.20071094

39. Zheng $Y$, Danilenko DM, Valdez $P$, et al. Interleukin-22, a T(H)17 cytokine, mediates IL-23-induced dermal inflammation and acanthosis. Nature. 2007:445:648-51. DOl:10.1038/nature05505

40. Becher B, Pantelyushin S. Hiding under the skin: interleukin-17-producing $\gamma \delta T$ cells go under the skin? Nat Med. 2012;18:1748-50. DOI:10.1038/nm.3016

41. Schmuth M, Moosbrugger-Martinz V, Blunder S, Dubrac S. Role of PPAR, LXR, and PXR in epidermal homeostasis and inflammation. Biochim Biophys Acta. 2014;1841:463-73. DOl:10.1016/j.bbalip.2013.11.012

42. Sher T, Yi HF, McBride OW, Gonzalez FJ. CDNA cloning, chromosomal mapping, and functional characterization of the human peroxisome proliferator activated receptor. Biochemistry. 1993;32:5598-604. DOl:10.1021/bi00072a015

43. Sertznig P, Reichrath J. Peroxisome Proliferator-activated receptors (PPARs) in dermatology: challenge and promise. Dermatoendocrinol. 2011;3:130-5. D0l:10.4161/derm.3.3.15025

44. Henson P. Suppression of macrophage inflammatory responses by PPARs. Proc Natl Acad Sci U S A. 2003;100:6295-6. DOI:10.1073/pnas.1232410100

45. Marx N, Kehrle B, Kohlhammer K, et al. PPAR activators as antiinflammatory mediators in human T lymphocytes: implications for atherosclerosis and transplantation-associated arteriosclerosis. Circ Res. 2002;90:703-10. DOl:10.1161/01.res.0000014225.20727.8f

46. Sobolev V, Nesterova A, Soboleva A, et al. The model of PPARY-downregulated signaling in psoriasis. PPAR Res. 2020;2020:1-11. DOl:10.1155/2020/6529057

47. Chighizola CB, Favalli EG, Meroni PL. Novel mechanisms of action of the biologicals in rheumatic diseases. Clin Rev Allergy Immunol. 2014;47:6-16. DOI:10.1007/s12016-013-8359-x

48. Денисова Е.В., Дениева М.И., Дворянкова Е.В., и др. К вопросу гепатотоксичности препаратов, применяемых в дерматологии. Врач. 2020;31:52-7 [Denisova EV, Denieva MI, Dvoryankova EV, et al. On hepatotoxicity of drugs used in dermatology. Vrach (Doctor). 2020;31:52-7 (in Russian)]. DOI:10.29296/25877305-2020-09-09

49. Пирузян А., Денисова Е., Дворянкова Е., и др. Комплексная патогенетическая терапия псориаза: купирование воспаления и коррекция метаболических нарушений. Врач. 2019;10:31-4 [Piruzyan A, Denisova E, Dvoryankova E, et al. Combination pathogenetic therapy for psoriasis: relief of inflammation and correction of metabolic disorders. Vrach. 2019;10:30-4 (in Russian)]. DOI:10.29296/25877305-2019-10-06

50. Денисова Е., Дворянкова Е., Дениева М., и др. Обоснование применения гепатопротекторов при псориазе. Врач. 2018;9:85-8 [Denisova E, Dvoryankova E, Denieva M, et al. Rationale for the use of hepatoprotective agents in the treatment of psoriasis. Vrach. 2018;9:85-8 (in Russian)]. DOl:10.29296/25877305-2018-09-20

Статья поступила в редакцию / The article received: 20.08.2021

Статья принята к печати / The article approved for publication: 11.10.2021

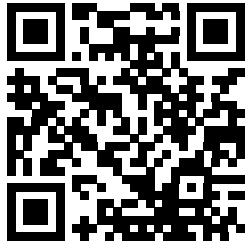

